\title{
Spectral Bio-indicator Simulations for Tracking Photosynthetic Activities in a Corn Field
}

\author{
Yen-Ben Cheng ${ }^{* a}$, Elizabeth M. Middleton ${ }^{\mathrm{b}}$, K. Fred Huemmrich ${ }^{\mathrm{c}}$, Qingyuan Zhang ${ }^{\mathrm{d}}$, Lawrence \\ Corp ${ }^{\mathrm{e}}$, Petya Campbell ${ }^{\mathrm{c}}$, William Kustas ${ }^{\mathrm{f}}$ \\ ${ }^{a}$ Earth Resources Technology, Inc., Laurel, MD, USA 20707; ${ }^{b}$ NASA Goddard Space Flight Center, \\ Greenbelt, MD, USA 20771; ' Joint Center for Earth Systems Technology, UMBC, Baltimore, MD, \\ USA 21228; ${ }^{\mathrm{d}}$ Universities Space Research Association, Columbia, MD, USA 21044; ${ }^{\mathrm{e}}$ Sigma Space

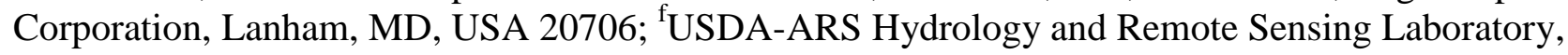 \\ Beltsville, MD, USA 20705
}

\begin{abstract}
Accurate assessment of vegetation canopy optical properties plays a critical role in monitoring natural and managed ecosystems under environmental changes. In this context, radiative transfer (RT) models simulating vegetation canopy reflectance have been demonstrated to be a powerful tool for understanding and estimating spectral bio-indicators. In this study, two narrow band spectroradiometers were utilized to acquire observations over corn canopies for two summers. These in situ spectral data were then used to validate a two-layer Markov chain-based canopy reflectance model for simulating the Photochemical Reflectance Index (PRI), which has been widely used in recent vegetation photosynthetic light use efficiency (LUE) studies. The in situ PRI derived from narrow band hyperspectral reflectance exhibited clear responses to: 1) viewing geometry which affects the asset of light environment; and 2) seasonal variation corresponding to the growth stage. The RT model (ACRM) successfully simulated the responses to the variable viewing geometry. The best simulations were obtained when the model was set to run in the two layer mode using the sunlit leaves as the upper layer and shaded leaves as the lower layer. Simulated PRI values yielded much better correlations to in situ observations when the cornfield was dominated by green foliage during the early growth, vegetative and reproductive stages $(\mathrm{r}=0.78$ to 0.86$)$ than in the later senescent stage $(r=0.65)$. Further sensitivity analyses were conducted to show the important influences of leaf area index (LAI) and the sunlit/shaded ratio on PRI observations.
\end{abstract}

Keywords: hyperspectral, radiative transfer, PRI, ACRM, sunlit canopy, shaded canopy, LUE

\section{INTRODUCTION}

Remotely sensed bio-indicators provide unique information in monitoring and modeling processes in time and space for our Earth's ecosystems. The exchange of carbon between the biosphere and the atmosphere has been a focus and a key challenge among various ecological processes in recent years $[1,2]$. One of the widely used concepts to model carbon assimilation by plants is based on the light use efficiency (LUE) [3, 4]. The LUE model simply describes carbon assimilation by plants, where gross primary production (GPP) or net primary production (NPP) is the product of the absorbed photosynthetically active radiation (APAR) and LUE. Previous studies have shown that LUE can vary by vegetation type, environmental conditions, and phenology or seasonality, which highlights the importance of understanding its variation in large scale carbon monitoring [1,5-7]. Efforts have been put towards development of various models to estimate LUE to improve carbon assimilation estimates. These methods typically utilize a look-up table of assumed maximum possible LUE which are down-scaled using meteorological data (e.g., air temperature and VPD) to derive an adjustment coefficient to account for sub-optimal environmental effects. Examples include the Moderate Resolution Imaging Spectroradiometer (MODIS) GPP product (MOD17) and the Vegetation Photosynthesis Model [8-12]. These meteorological data usually have a much larger footprint than the area of interest, and are not always representative of the local LUE [1]. Hence, errors can be introduced to LUE estimates due to uncertainties associated with these meteorological data. An alternative approach to derive LUE is based on a bio-indicator to directly track and provide an estimate of LUE. This remote sensing method provides us with an opportunity to derive a LUE estimate that is directly linked with physiological and phenological condition of the plants, without needing meteorological information.

*Yen-Ben.Cheng@nasa.gov 
One such spectral bio-indicator is the Photochemical Reflectance Index (PRI) which has been shown to track the foliages' xanthophyll cycle [13-15], one of the photoprotective processes to dispense excessive absorbed solar radiation. Since this information can be used to model the down-regulation of photosynthesis [16], the PRI has been increasingly used and examined for its correlation with LUE across various vegetation types and scales [1, 2, 13-15, 17-22]. Nevertheless, studies have reported various confounding factors -- including viewing geometry, canopy structure, LAI, shadow faction, soil background reflectance, and pigment levels -- that affect the PRI values, as well as the relationship between PRI and LUE at canopy or ecosystem scales [20, 21, 23-32]. Furthermore, previous studies have shown the importance of taking both sunlit and shaded leaves into account to explain the behavior of PRI at canopy level [21]since sunlit foliage is more likely to experience higher environmental stress (e.g. higher temperature, more solar radiation) and has lower LUE. Hence, taking only sunlit foliage into account might result in underestimation of actual LUE at canopy and ecosystem scales [20,21].

Therefore, in this study, we utilized a radiative transfer (RT) model to improve our knowledge regarding how the PRI values and the PRI:LUE relationships change in response to various potentially confounding effects. RT models provide a powerful tool to study this topic since they are designed to quantitatively examine how vegetation optical properties change with leaf biochemical and canopy biophysical properties [33-36]. The PRI at canopy level was previously examined using the PROSPECT leaf model linked with the SAILh and FLGHT canopy RT models to produce a nonstressed version of the PRI in a crop water stress study [37]. In our current study, we linked in situ leaf optical properties with a two layer Markov-Chain canopy reflectance model (ACRM) [38-40] to simulate actual PRI for corn crop canopies through three different growth stages: young and vegetative, mature and productive, and early senescence. We also investigated how canopy structure and vertical distribution of sunlit and shaded leaves in the canopy affected PRI values.

\section{METHODS}

\subsection{Study site and data collection}

During the summers of 2008 and 2010, field campaigns were conducted on corn (Zea mays L.) in the Optimizing Production Inputs for Economic and Environmental Enhancement (OPE3) cornfield $\left(39.030^{\circ} \mathrm{N}, 76.845^{\circ} \mathrm{W}\right)$ maintained by the USDA Beltsville Agricultural Research Center (BARC) located in Maryland, U.S.A. The field is approximately $24 \mathrm{~km}$ northeast of Washington DC. The 2008 crop was planted later than usual due to a wet springtime. Measurements were acquired on four dates representing different growth stages at vegetative $(\mathrm{V} 9,10)$, reproductive (R3, grain filling) and early senescent (R4) stages: August $1^{\text {st }}, 2008$ (V10 = ten leaves expanded); July $1^{\text {st }}, 2010$ (V9); July $15^{\text {th }}, 2010$ (R3); and August $9^{\text {th }}, 2010$ (R4). The observations were taken along a 100-m north-south direction transect in the middle of the cornfield to minimize disturbance to the field and to maintain representativeness of the data. Hyperspectral reflectance was acquired for vegetation at both leaf and canopy levels, and on bare soil using a FieldSpec Spectroradiometer (ASD Inc., Boudler, CO, USA) and an USB4000 Miniature Fiber Optic Spectrometer (Ocean Optics Inc., Dunedin, FL, USA). At leaf level, a Li-Cor 1800-12 integrating sphere (Li-Cor, Lincoln, NE, USA) was also utilized to determine spectral reflectance and transmittance on excised leaves. At canopy level, the reflectance was determined at various viewing geometries defined by view zenith angle $\left(\theta_{\mathrm{v}}\right)$ and relative azimuth angle $(\psi)$. Three different $\theta_{\mathrm{v}}\left(30^{\circ}, 45^{\circ}\right.$, and $\left.60^{\circ}\right)$ were coupled with eight different $\psi\left(0^{\circ}\right.$ to $315^{\circ}$ relative to the sun, at $45^{\circ}$ increments). Nadir measurements (i.e., $\theta_{\mathrm{v}}=0^{\circ} ; \psi=0^{\circ}$ ) were also included. Canopy radiances were acquired at $1.58,1.04,0.86$ meters, respectively, above the canopy for the three $\theta_{\mathrm{v}}$, which made a consistent center of the field of view (FOV) at approximately $0.75 \mathrm{~m}$ from the sensor. Reflectances were calculated as the ratio of canopy radiances to those acquired over a Spectralon reference panel (Labsphere, North Sutton, NH, USA). Soil background reflectance was similarly determined for bare soil at nadir. Measurements were taken between $9 \mathrm{am}$ to $4 \mathrm{pm}$ local time, during which solar zenith angles $(\theta \mathrm{s})$ varied between $16.6^{\circ}$ and $51.2^{\circ}$. Leaf Area Index (LAI) was also measured for the corn canopies with a LiCor LAI-2000 plant canopy analyzer (Li-Cor, Lincoln, NE, USA).

\subsection{Model description}

In this study, the ACRM canopy RT model [38-40] was utilized to simulate PRI, which was calculated as a normalized difference index using two narrow $(\sim 3 \mathrm{~nm})$ green bands centered at 531 and $570 \mathrm{~nm}$, as [R531-R570]/[R531+R570]. This canopy RT model implements an enhanced bidirectional gap probability function to account for canopies where leaves are fixed to erect stalks and/or long narrow leaves which stretch through several sub-layers of the canopy [39]. These features make the ACRM perfectly suitable to simulate corn canopies. The model has been used in various studies 
including both forward and inversion modes to validate and/or to estimate plants biochemical properties at leaf and/or canopy levels [33, 41, 42]. The ACRM model was set to couple with in situ leaf optical properties and soil background spectra and to run in its forward mode to simulate canopy reflectance at various viewing geometries. The model was also set to run in the two layer mode using leaf optical properties from sunlit leaves as the upper layer and shaded leaves as the lower layer of the canopy. PRI was then derived from the simulated reflectance spectra and validated by comparing with the PRI derived from in situ canopy reflectance spectra. Values of other essential input parameters for the models were decided based on previous studies [33, 34, 41-43] and are summarized in Table 1.

This study extends the progress in examining and understanding how LAI affects ACRM-simulated PRI values. The dataset acquired on July 15, 2010 was selected as an example. First, we set various LAI values as input to examine how simulated PRI values changed accordingly. Second, we investigated how the distribution of LAI between the upper and the lower layer of the canopy affects simulated PRI values. The sensitivity analysis was done by changing the ratio of upper/lower layer LAI values between $80 / 20$ and 20/80. This ratio of upper/lower canopy layer LAI is also associated with the ratio between sunlit/shaded leaves used in the simulations since leaf optical properties of sunlit leaves were used in the upper layer while lower layer was simulated using shaded leaves.

Table 1. Value ranges for parameters used as input to ACRM in this study

\begin{tabular}{|l|l|l|l|l|}
\hline Date & August 1,2008 & July 1,2010 & July 15,2010 & August 9,2010 \\
\hline LAI & 2.60 & 1.92 & 2.48 & 1.81 \\
\hline Solar zenith angle $\left(\theta_{\mathrm{s}}\right)$ & $21.6^{\circ}$ to $44.6^{\circ}$ & $16.6^{\circ}$ to $42.8^{\circ}$ & $18.1^{\circ}$ to $45.3^{\circ}$ & $24.1^{\circ}$ to $51.2^{\circ}$ \\
\hline View zenith angle $\left(\theta_{\mathrm{v}}\right)$ & \multicolumn{3}{|c|}{$0^{\circ}$ or $30^{\circ}$ or $45^{\circ}$ or $60^{\circ}$} \\
\hline Relative leaf size $(\mathrm{sl})$ & \multicolumn{3}{|c|}{0.01} \\
\hline Markov parameter $(\mathrm{clz})$ & \multicolumn{3}{|c|}{1.5} \\
\hline $\begin{array}{l}\text { Leaf angle distribution } \\
\text { parameter }\end{array}$ & \multicolumn{3}{|c|}{$\begin{array}{c}\text { Eln }=0 ; \mathrm{Thm}=45^{\circ} \\
\text { (used to describe canopy structure) }\end{array}$} \\
\hline
\end{tabular}

\section{RESULTS}

\subsection{In situ leaf and canopy observations}

The PRI values at leaf level were categorized into sunlit and shaded leaves and are summarized in Figure 1. The PRI for sunlit leaves consistently exhibited statistically significantly lower values than shaded leaves on all four field campaign days. Sunlit leaves are more likely to experience environmental stress (e.g., exposed to higher level of solar radiation and air temperature) that lead to photosynthetic down-regulation, and hence, have lower PRI values than shaded leaves. Less environmental moisture stress (i.e., higher PRI values) was indicated for the 2008 data set, in response to a wet spring (e.g., PRI was positive and reached +0.07 in shaded leaves, compared to similar growth stage in 2010 when PRI was zero).

At the canopy level, in situ PRI was plotted against viewing geometry $\left(\theta_{\mathrm{v}}\right.$ and $\left.\psi\right)$ in Figure 2. Observed PRI values exhibited clear dependence on viewing geometry. The highest PRI values were obtained when $\psi$ was close to $180^{\circ}$, the cold (or dark) spot in the solar principal plane which is usually dominated by shaded leaves. The lowest PRI values were obtained when $\psi$ was close to the hot (or bright) spot on the solar principal plane (e.g., $0^{\circ}$ or $315^{\circ}$ ), where the canopy is dominated by sunlit leaves. At the R3 growth stage in 2010, the PRI exhibited slightly higher values from -0.02 to $\sim 0.01$. These findings are consistent with results represented in previous studies [20, 21, 25, 27]. PRI values also increased by $>1$ unit in low stress conditions (8/1/2008) but up to 1.5 PRI units in the more stressed 2010 datasets when $\theta_{\mathrm{v}}$ increased. This might result from less soil background contamination when measurements were taken at oblique angles, since bare soil usually has much lower PRI values than green vegetation, or because more shaded lower, foliage is viewed from the side. 


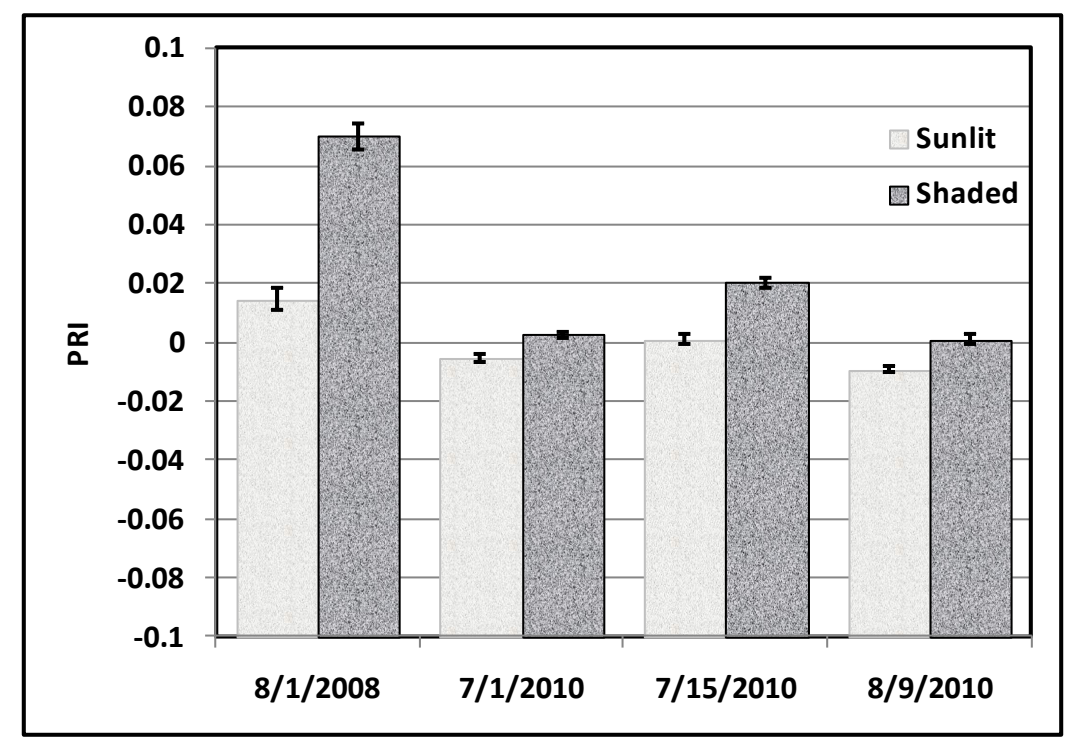

Figure 1. In situ PRI values for sunlit and shaded leaves on the four days of field campaign: August $1^{\text {st }} 2008$, July $1^{\text {st }} 2010$, July $15^{\text {th }} 2010$, and August $9^{\text {th }} 2010$. Values are shown as mean \pm S.E. The values for $8 / 1 / 2008$ and $7 / 1 / 2010$ were acquired at similar growth stages but 2008 had a wet spring that delayed planting, and 2010 was a drier year.

\subsection{ACRM-simulated PRI}

Simulated PRI values were calculated using output spectra from ACRM and were plotted alongside in situ PRI for validation purposes in Figure 2. The ACRM-simulated PRI successfully captured the response that in situ PRI exhibited to $\theta_{\mathrm{v}}$ and $\psi$ (Figure 3), with the lowest values occurring when $\psi$ was $\sim 0^{\circ}$ (the sunlit foliage sector) and higher values when $\psi$ was $\sim 180^{\circ}$ (the shaded foliage sector). Moreover, the magnitude of both simulated and observed PRI values also increased when $\theta_{\mathrm{v}}$ increased. Simulated PRI values were plotted against observed PRI values in Figure 3. On individual days, the best agreement between in situ and simulated PRI was found on 8/1/2008 $(\mathrm{r}=0.86$; RMSE $=0.004 ; \mathrm{n}=171)$ followed by 7/15/2010 $(\mathrm{r}=0.87$; RMSE $=0.005 ; \mathrm{n}=117)$ and 7/1/2010 $(\mathrm{r}=0.78 ; \mathrm{RMSE}=0.005 ; \mathrm{n}=149)$. The least satisfactory result was found on $8 / 9 / 2010(\mathrm{r}=0.65$; RMSE $=0.010 ; \mathrm{n}=176)$. The corn crop was in the young and vegetative stage on 8/1/2008 and 7/1/2010. For both years, ACRM delivered similar performance for PRI simulations. On 7/15/2010, the corn crop was mature and reproductive. Similarly, ACRM was able to deliver good PRI simulations. When the corn crop reached the early senescence stage (8/9/2010), simulations from ACRM were satisfactory but much less so than at earlier stages. Therefore, it might suggest that ACRM performed the best for corn crops dominated by green foliage. When the crop reaches the early senescence stage, the canopy is likely to contain both green and dead leaves and the canopy reflectance is also more likely to be contaminated by soil background. Therefore, the performance of ACRM decreased because of the complexity associated with the mixed senescent conditions. Nevertheless, when all the data were analyzed together (Fig. 3), the ACRM-simulated PRI yielded a strong correlation to field observations $(\mathrm{r}=$ $0.94 ; \mathrm{RMSE}=0.007 ; \mathrm{n}=613$ ).

\subsection{Canopy structure and PRI simulations}

A sensitivity analysis was conducted to investigate how an important canopy structure parameter, LAI, would affect PRI values in the ACRM simulation scheme. Figure 4a summarized how total canopy LAI values affected simulated PRI values. First of all, PRI values increased when LAI increased. Secondly, the most significant changes in PRI values occurred when LAI increased from 0.5 to 2.48 , during which PRI increased by 4 PRI units (e.g., from -0.03 to +0.01 ). PRI was little affected by increases in total LAI above 2.48 . These results suggest that when LAI initially increased, less soil background contaminated the simulated spectra, increasing PRI values. However, PRI values also increased when $\theta_{\mathrm{v}}$ increased from $30^{\circ}$ to $60^{\circ}$. And, in contrast to increasing LAI effects on PRI, $\theta_{v}$ effects were consistent at all LAI levels (increasing one PRI unit, e.g., 0.0 to +0.01 ) and persisted at the higher LAI, due to inclusion of more shaded (i.e., less stressed) foliage at oblique views. 


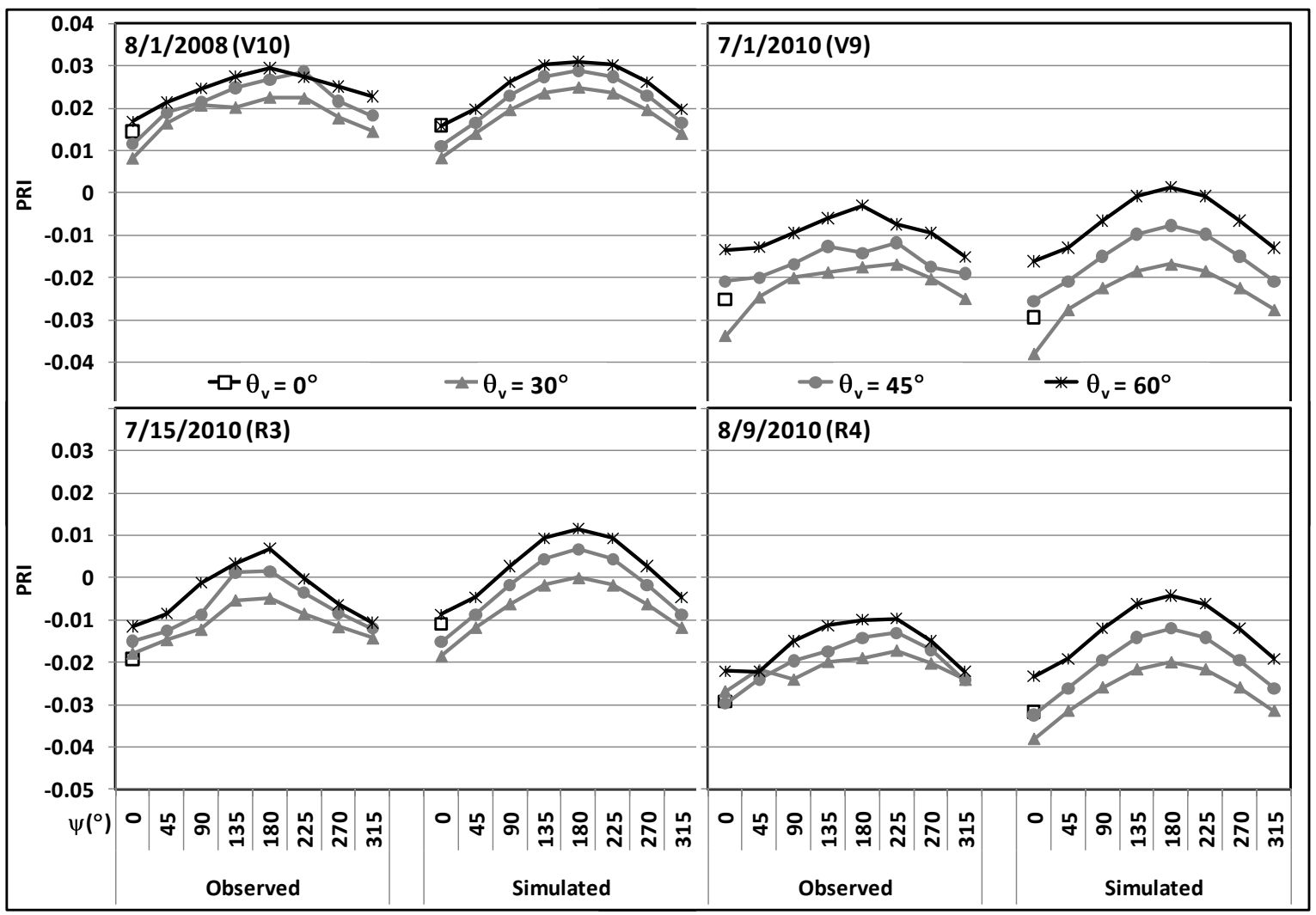

Figure 2. Observed in situ versus ACRM-simulated canopy PRI values corresponding to different combinations of viewing geometry $\left(\theta_{\mathrm{v}}\right.$ and $\left.\psi\right)$ for the four field campaign days are shown. Three curves $(\Delta, \Theta, *)$ represent $\theta_{\mathrm{v}}$ at $30^{\circ}, 45^{\circ}$, and $60^{\circ}$ respectively, for the azimuthal observations $\left(\psi\right.$ at $0^{\circ}, 45^{\circ}, 90^{\circ}, 135^{\circ}, 180^{\circ}, 225^{\circ}, 270^{\circ}$, and $\left.315^{\circ}\right)$, and the nadir observation $\left(\theta_{\mathrm{v}}=0^{\circ} ; \psi=0^{\circ}, \square\right)$ is also included.

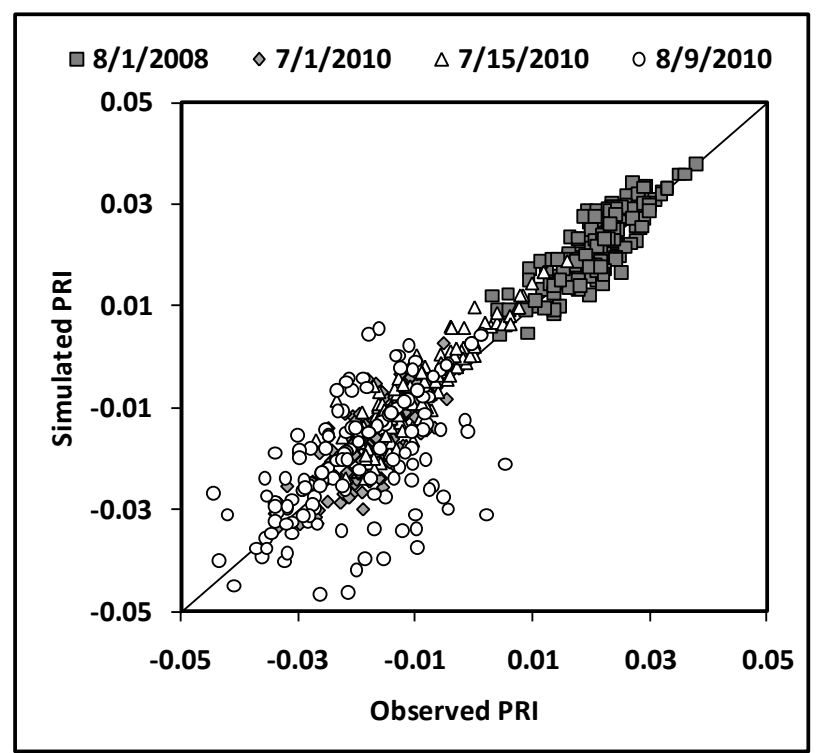

Figure 3. Correlation between observed and simulated canopy PRI values over the four field campaign days $(r=$ $0.94 ; \mathrm{RMSE}=0.007 ; \mathrm{n}=613$ ). 


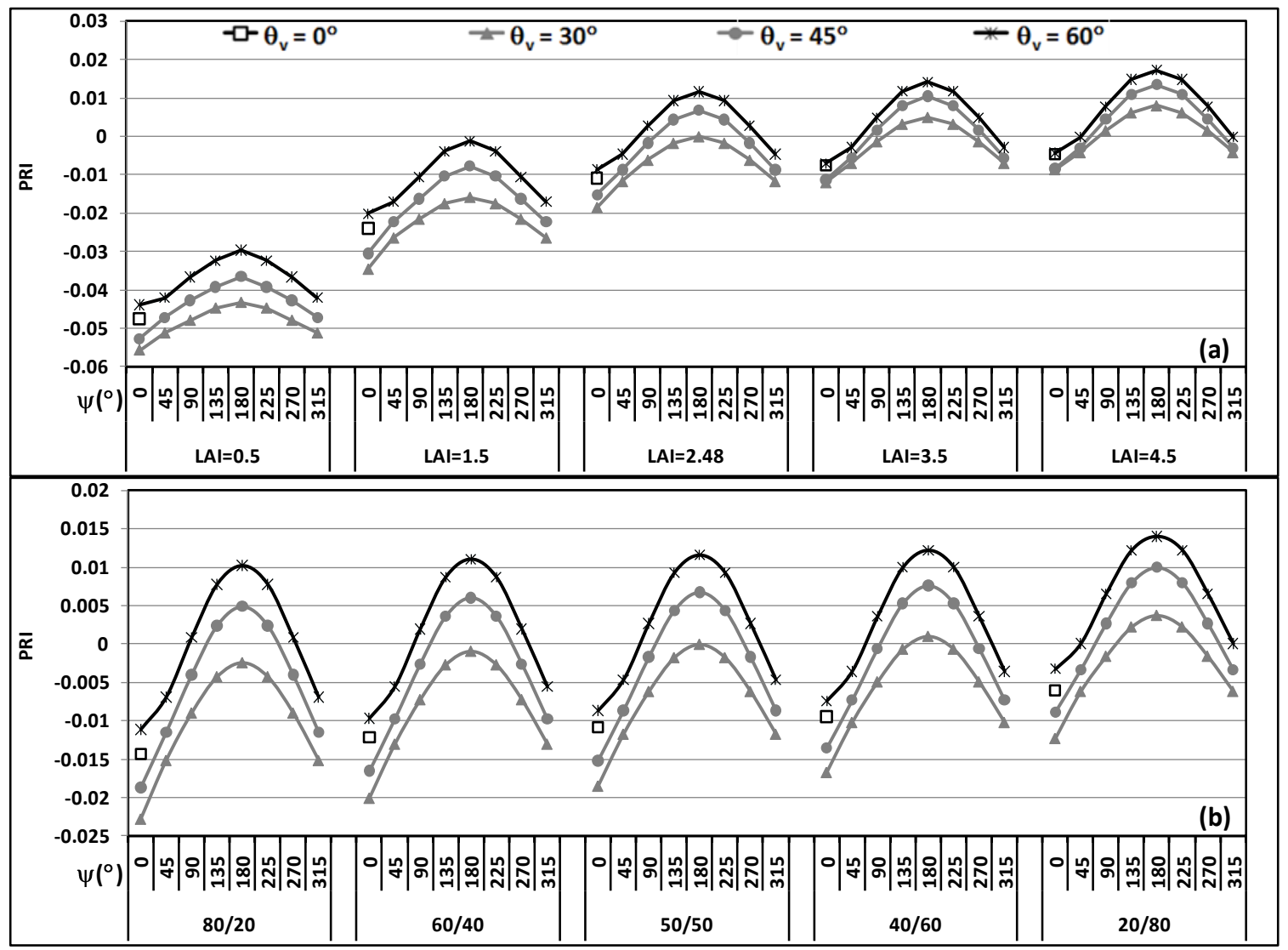

Figure 4. Sensitivity analysis of (a) LAI values; (b) sunlit/shaded ratio on simulated PRI values using ACRM for various viewing geometry combinations. Three curves $\left(\Delta, \Theta^{*}\right)$ represent $\theta_{\mathrm{v}}$ at $30^{\circ}, 45^{\circ}$, and $60^{\circ}$ respectively, for the azimuthal observations $\left(\psi\right.$ at $0^{\circ}, 45 \mathrm{o}, 90^{\circ}, 135^{\circ}, 180^{\circ}, 225^{\circ}, 270^{\circ}$, and $\left.315^{\circ}\right)$, and the nadir observation $\left(\theta_{\mathrm{v}}=0\right.$; $\psi=0, \square)$ is also included. Note that the PRI scales differ in (a) vs. (b).

These effects related to varying amounts of sunlit and shaded foliage captured in the spectral observations can be further examined with the ACRM model in the two layer mode, where the upper/lower canopy layer ratio can be used to represent the vertical distribution of LAI within the canopy. Since sunlit leaf optical properties were utilized for the upper layer and shaded leaves for the lower layer, this ratio would also be associated with the sunlit/shaded ratio for the canopy segment of interest. In Figure 4b, we summarized how this sunlit/shaded ratio affected PRI simulations. When the ratio changed from $80 / 20$ to $20 / 80$ (in $20 \%$ increment), meaning the contribution to PRI simulations from shaded leaf optical properties became higher, and simulated PRI values increased by one PRI unit (e.g., -0.023 to $-0.012 ; \theta_{v}=30^{\circ} ; \psi$ $=0^{\circ}$ ). Since shaded leaves had higher PRI values than sunlit leaves, as shown in Figure 1, this was as expected. Furthermore, similar to the results in Figure 4a, changes in the sunlit/shaded ratio did not change the correlations between PRI values and $\theta_{\mathrm{v}}$. This showed once again the importance of taking both sunlit and shaded leaves into account in understanding and simulating PRI. Moreover, for most vegetation, canopy structure (e.g., total LAI) and its vertical distribution within the canopy changes throughout the growing season. Therefore, in the future more effort should be put towards investigating the relationship between PRI and canopy structure and consideration of sunlit/shaded sectors.

\section{SUMMARY}

In this study, we demonstrated the opportunity of simulating PRI for corn crop canopies by linking in situ leaf optical properties with a two layer Markov-chain canopy reflectance model (ACRM). The ACRM successfully simulated the PRI values and directional trends through various growth stages when we utilized sunlit leaves as the upper layer and 
shaded leaves as the lower layer of the canopy. Moreover, the ACRM was capable of accurately describing the impacts on PRI due to viewing geometry and reproducing the observations made under field conditions. This success shows the importance of taking both sunlit and shaded leaves into account to improve our understanding about how to interpret the PRI's role in describing photosynthetic function such as LUE. Furthermore, we investigated how a canopy structure parameter (LAI) affects PRI values. This RT model based simulation presents a new scheme for better interpretations of PRI information and potentially leads to improved carbon monitoring and modeling.

\section{REFERENCES}

[1] E. M. Middleton, K. F. Huemmrich, Y.-B. Cheng and H. A. Margolis, "Spectral bio-indicators of photosynthetic efficiency and vegetation stress," in Hyperspectral Remote Sensing of Vegetation P. S. Thenkabail, J. G. Lyon and A. Huete, Eds., Taylor and Francis (2011).

[2] M. F. Garbulsky, J. Peñuelas, J. Gamon, Y. Inoue and I. Filella, "The photochemical reflectance index (PRI) and the remote sensing of leaf, canopy and ecosystem radiation use efficiencies: A review and meta-analysis," Remote Sensing of Environment 115(2), 281-297 (2011) [doi:10.1016/j.rse.2010.08.023].

[3] J. Monteith, "Solar-radiation and productivity in tropical ecosystems," Journal of Applied Ecology 9(747-766 (1972).

[4] J. Monteith, "Climate and efficiency of crop production in Britain," Philosophical Transaction of the Royal Society of London B: Biological Sciences 281(271-294 (1977).

[5] M. C. Anderson, J. M. Norman, T. P. Meyers and G. R. Diak, "An analytical model for estimating canopy transpiration and carbon assimilation fluxes based on canopy light-use efficiency," Agricultural and Forest Meteorology 101(4), 265-289 (2000) [doi:10.1016/s0168-1923(99)00170-7].

[6] S. T. Gower, C. J. Kucharik and J. M. Norman, "Direct and indirect estimation of leaf area index, fAPAR, and net primary production of terrestrial ecosystems," Remote Sensing of Environment 70(1), 29-51 (1999) [doi:Doi: 10.1016/s0034-4257(99)00056-5].

[7] J. C. Lin, M. R. Pejam, E. Chan, S. C. Wofsy, E. W. Gottlieb, H. A. Margolis and J. H. McCaughey, "Attributing uncertainites in simulated biospheric carbon fluxes to different error sources," Global Biogeochemical Cycles (in press) (2011).

[8] B. E. Law and R. H. Waring, "Combining remote sensing and climatic data to estimate net primary production across Oregon," Anglais 4(4), 717-728 (1994).

[9] P. Mahadevan, S. C. Wofsy, D. M. Matross, X. Xiao, A. L. Dunn, J. C. Lin, C. Gerbig, J. W. Munger, V. Y. Chow and E. W. Gottlieb, "A satellite-based biosphere parameterization for net ecosystem $\mathrm{CO} 2$ exchange: Vegetation Photosynthesis and Respiration Model (VPRM)," Global Biogeochem. Cycles 22(2), GB2005 (2008) [doi:10.1029/2006gb002735].

[10] S. D. Prince and S. N. Goward, "Global primary production: A remote sensing approach," Journal of Biogeography 22(4-5), 815-835 (1995).

[11]F. A. Heinsch, M. C. Reeves, P. Votava, S. Kang, C. Milesi, M. Zhao, J. Glassy, W. M. Jolly, R. Loehman, C. F. Bowker, J. S. Kimball, R. R. Nemani and S. W. Running, "User's Guide: GPP and NPP (MOD17A2/A3) Products, NASA MODIS Land Algorithm," University of Motana, Missoula, MT ( (2003) [doi:http://www.ntsg.umt.edu/modis/MOD17UsersGuide.pdf].

[12] X. Xiao, Q. Zhang, B. Braswell, S. Urbanski, S. Boles, S. Wofsy, B. Moore III and D. Ojima, "Modeling gross primary production of temperate deciduous broadleaf forest using satellite images and climate data," in Rem. Sensing Environ., pp. 256-270 (2004).

[13] J. A. Gamon, C. B. Field, D. A. Roberts, S. L. Ustin and R. Valentini, "Functional patterns in an annual grassland during an AVIRIS overflight," Remote Sensing of Environment 44(2/3), 239-253 (1993) [doi:doi:10.1016/00344257(93)90019-T].

[14]J. A. Gamon, J. Penuelas and C. B. Field, "A narrow-waveband spectral index that tracks diurnal changes in photosynthetic efficiency," Remote Sensing of Environment 41(1), 35-44 (1992).

[15] J. A. Gamon, L. Serrano and J. S. Surfus, "The photochemical reflectance index: an optical indicator of photosynthetic radiation use efficiency across species, functional types, and nutrient levels," Oecologia 112(4), 492-501 (1997).

[16] B. Demmig-Adams and W. W. Adams III, "The role of xanthophyll cycle carotenoids in the protection of photosynthesis," Trends in Plant Science 1(1), 21-26 (1996). 
[17] J. Peñuelas, J. Llusia, J. Pinol and I. Filella, "Photochemical reflectance index and leaf photosynthetic radiation-useeffeciency assessment in Mediterranean trees," International Journal of Remote Sensing 18(13), 2863-2868 (1997).

[18] I. Filella, T. Amaro, J. L. Araus and J. Peñuelas, "Relationship between photosynthetic radiation-use efficiency of barley canopies and the photochemical reflectance index (PRI)," Physiologia Plantarum 96(2), 211-216 (1996) [doi:doi:10.1111/j.1399-3054.1996.tb00204.x].

[19] Y. Inoue, J. Peñuelas, A. Miyata and M. Mano, "Normalized difference spectral indices for estimating photosynthetic efficiency and capacity at a canopy scale derived from hyperspectral and $\mathrm{CO} 2$ flux measurements in rice," Remote Sensing of Environment 112(1), 156-172 (2008).

[20] Y.-B. Cheng, E. M. Middleton, T. Hilker, N. C. Coops, P. Krishnan and T. A. Black, "Dynamics of spectral bioindicators and their correlations with light use efficiency using directional observations at a Douglas-fir forest," Measurement Science and Technology 20(9), 095107 (2009) [doi:10.1088/0957-0233/20/9/095107].

[21]E. M. Middleton, Y.-B. Cheng, T. Hilker, T. A. Black, P. Krishnan, N. C. Coops and K. F. Huemmrich, "Linking foliage spectral responses to canopy level ecosystem photosynthetic light use efficiency at a Douglas-fir forest in Canada," Canadian Journal of Remote Sensing 35 ( 2), 166-188 (2009).

[22] K. F. Huemmrich, L. Corp, A. Russ, E. Middleton, W. Kustas, J. Prueger and Y.-B. Cheng, "Using reflectance measurements to determine light use efficiency in corn," presented at IEEE International Geoscience \& Remote Sensing Symposium (IGARSS), July 6-11, 2008, Boston, MA, USA.

[23] D. A. Sims, H. Luo, S. Hastings, W. C. Oechel, A. F. Rahman and J. A. Gamon, "Parallel adjustments in vegetation greenness and ecosystem CO2 exchange in response to drought in a Southern California chaparral ecosystem," Remote Sensing of Environment 103(3), 289-303 (2006) [doi:DOI: 10.1016/j.rse.2005.01.020].

[24] G. G. Drolet, K. F. Huemmrich, F. G. Hall, E. M. Middleton, T. A. Black, A. G. Barr and H. A. Margolis, "A MODIS-derived photochemical reflectance index to detect inter-annual variations in the photosynthetic light-use efficiency of a boreal deciduous forest," Remote Sensing of Environment 98(2-3), 212-224 (2005).

[25]F. G. Hall, T. Hilker, N. C. Coops, A. Lyapustin, K. F. Huemmrich, E. Middleton, H. Margolis, G. Drolet and T. A. Black, "Multi-angle remote sensing of forest light use efficiency by observing PRI variation with canopy shadow fraction," Remote Sensing of Environment 112(7), 3201-3211 (2008).

[26] T. Hilker, N. C. Coops, F. G. Hall, T. A. Black, B. Chen, P. Krishnan, M. A. Wulder, P. J. Sellers, E. M. Middleton and K. F. Huemmrich, "A modeling approach for upscaling gross ecosystem production to the landscape scale using remote sensing data," Journal of Geophysical Research - Biogeosciences 113(G03006 (2008) [doi:10.1029/2007JG000666].

[27] T. Hilker, N. C. Coops, F. G. Hall, T. A. Black, M. A. Wulder, Z. Nesic and P. Krishnan, "Separating physiologically and directionally induced changes in PRI using BRDF models," Remote Sensing of Environment 112(6), 2777-2788 (2008).

[28]C. V. M. Barton and P. R. J. North, "Remote sensing of canopy light use efficiency using the photochemical reflectance index: Model and sensitivity analysis," Remote Sensing of Environment 78(3), 264-273 (2001).

[29] J. Gamon, C. Field, A. Fredeen and S. Thayer, "Assessing photosynthetic downregulation in sunflower stands with an optically-based model," Photosynthesis Research 67(1), 113-125 (2001).

[30]D. A. Sims and J. A. Gamon, "Relationships between leaf pigment content and spectral reflectance across a wide range of species, leaf structures and developmental stages," Remote Sensing of Environment 81(2-3), 337-354 (2002) [doi:doi:10.1016/S0034-4257(02)00010-X].

[31] Stylinski, Gamon and Oechel, "Seasonal patterns of reflectance indices, carotenoid pigments and photosynthesis of evergreen chaparral species," Oecologia 131(3), 366-374 (2002) [doi:10.1007/s00442-002-0905-9].

[32]L. Suárez, P. J. Zarco-Tejada, G. Sepulcre-Cantó, O. Pérez-Priego, J. R. Miller, J. C. Jiménez-Muñoz and J. Sobrino, "Assessing canopy PRI for water stress detection with diurnal airborne imagery," Remote Sensing of Environment 112(2), 560-575 (2008).

[33] Y.-B. Cheng, P. J. Zarco-Tejada, D. Riano, C. A. Rueda and S. L. Ustin, "Estimating vegetation water content with hyperspectral data for different canopy scenarios: Relationships between AVIRIS and MODIS indexes," Rem. Sensing Environ. 105(4), 354-366 (2006) [doi:doi:10.1016/j.rse.2006.07.005].

[34] P. J. Zarco-Tejada, C. A. Rueda and S. L. Ustin, "Water content estimation in vegetation with MODIS reflectance data and model inversion methods," Rem. Sensing Environ. 85(1), 109-124 (2003) [doi:doi:10.1016/S00344257(02)00197-9].

[35] S. Jacquemoud, S. L. Ustin, J. Verdebout, G. Schmuck, G. Andreoli and B. Hosgood, "Estimating leaf biochemistry using the PROSPECT leaf optical properties model," Rem. Sensing Environ. 56(3), 194-202 (1996) [doi:doi:10.1016/0034-4257(95)00238-3]. 
[36] W. Verhoef, "Light scattering by leaf layers with application to canopy reflectance modeling: The SAIL model," in Rem. Sensing Environ., pp. 125-141 (1984).

[37]L. Suárez, P. J. Zarco-Tejada, J. A. J. Berni, V. González-Dugo and E. Fereres, "Modelling PRI for water stress detection using radiative transfer models," Remote Sensing of Environment 113(4), 730-744 (2009).

[38] A. Kuusk, "A fast, invertible canopy reflectance model," Rem. Sensing Environ. 51(3), 342-350 (1995).

[39] A. Kuusk, "A Markov chain model of canopy reflectance," Ag. For. Meteorol. 76(3-4), 221-236 (1995).

[40] A. Kuusk, "A two-layer canopy reflectance model," J. Quantitative Spectroscopy Radiative Transfer 71(1), 1-9 (2001).

[41]H. Fang, S. Liang and A. Kuusk, "Retrieving leaf area index using a genetic algorithm with a canopy radiative transfer model," Rem. Sensing Environ. 85(3), 257-270 (2003).

[42] R. Houborg, M. Anderson and C. Daughtry, "Utility of an image-based canopy reflectance modeling tool for remote estimation of LAI and leaf chlorophyll content at the field scale," Rem. Sensing Environ. 113(1), 259-274 (2009).

[43] S. Jacquemoud, "Inversion of the PROSPECT + SAIL Canopy Reflectance Model from AVIRIS Equivalent Spectra: Theoretical Study," Rem. Sensing Environ. 44(2/3), 281-292 (1993).

[44] 